\title{
Lifelong Religion and Change
}

\section{Producing Continuums of Practice}

Many existing applications of the concept of habitus within religious scholarship focus on processes of conscious habituation (e.g., Coleman 2000; Csordas 1994; Fer 2010; Shanneik 2011; Winchester 2008). In these processes, a new habitus is more or less intentionally learned in connection with some kind of religious realignment. Habitus, however, can evolve in adult life irrespective of conscious effort (Bourdieu and Wacquant 1992, 136; Bourdieu 199ob, 56). In this chapter, I examine some of the later evolutions of my interviewees' habitus, caused by changes in their overall social surroundings. While the Orthodox women had not actively changed their own affinities, most of them had married a member of another Christian domination. Moreover, in the course of their lives, the Finnish society had gone through radical realignments. The interview accounts do not contain many explicit descriptions of the effects of societal developments like secularization on domestic religious practice. This is understandable, since the grass-roots influences of such phenomena are not unequivocal or easily grasped. Hence, I approach the topic by taking a closer look at the informants' perceptions of contemporary religion, which convey their experiences as members of an increasingly differentiated society. I begin by discussing their depictions of their present-day religion.

It was common for the displaced Karelian Orthodox women to emphasize the historical continuity of Orthodox practices. They regularly made note of the old age of particular customs to argue for their authenticity. Senja, for example, described the daily prayers of her childhood home by explaining: "They've all gone around for hundreds of years. Prayers that are part of evenings and mornings and mealtime prayers, they're all straight from the Bible." Senja's reference to the Bible functions as a rhetorical strategy to legitimate her childhood prayer practices and to argue for the general invariance of Orthodox Christianity. Orthodox prayers do often quote scripture; however, they are not "all straight" from the Bible (Binns 2005, 49-51; Lash 2008, 35-36).

The legitimating effect of the rhetoric of continuity is especially clear in the women's accounts concerning more controversial issues within Orthodox doctrine. The ban on female ordination was one aspect of Orthodox Christianity that often triggered references to the constancy of Orthodoxy. In this vein, Raili, for instance, stated: “I don't approve of women priests. In my workplace 
I was a real advocate of women's rights. But I want something to remain the same even for my great-grandchildren. [I want] this Orthodox religion to have traditions, like in the olden days." About a third of the women responded positively to female ordination; nevertheless, even for many of these informants the emphasis on the continuum of traditions counted against women's priesthood. It was an argument they could understand and accept. ${ }^{1}$

According to Danièle Hervieu-Léger (2000, 81-82), religious belief revolves around the idea of a chain of memory connecting together past, present, and future believers. Individual religions, for their part, constitute systems through which this idea is "constituted, maintained, developed and controlled." In their accounts concerning the stability of Orthodox practices across time, also the women of my study evoked the notion of an Orthodox Christian chain of memory. However, they also established chains of religious memory of a more personal nature. These continuums usually stretched between their childhood and today. Thus, it was not uncommon for the women to refer to their religion as "childhood religion." Furthermore, when describing their present-day religious activities, they frequently linked these to similar practices and beliefs in their childhood homes. They often explained their observation of a particular practice, for instance, by noting how they had been doing so "ever since childhood," how they had "learned it when little," or how it was what their mothers had done. In the women's parlance, that is to say, reference to childhood legitimated religious activities. Allusion to a custom either having or having not been part of one's childhood religion sufficed to explain its importance or irrelevance in later life.

Helena: The Virgin Mary, or the Mother of God, is also a figure that is central in Orthodoxy. Does she have a special meaning to you?

Lyyli: No, no.

Helena: Right ... You haven't found her, like, particularly important?

1 In the Finnish Orthodox Church, the issue of women's ordination has not been widely discussed. However, some of the Church's highest officials have recently expressed somewhat differing views on the topic. While Archbishop Leo of Karelia and all Finland has stated that women's priesthood in the Orthodox Church is an impossibility, Metropolitan Ambrosius of Helsinki maintains that the question remains open within the Church (Hiiro 2015; Vihavainen 2015). The Evangelical Lutheran Church's decision to allow women to become priests was strongly criticized by the leading Orthodox clergy at the time (Laitila 2006, 174). In the long run, it has not markedly affected ecumenical relations between the Churches. 
Lyyli: No, no. (...) And neither did we at home. It stems from there. But they (her parents) were Orthodox. It was just ordinary family life without anything special.

In the above question, I define the veneration of Mary as an "Orthodox" practice. This prompts Lyyli to defend her own religiosity, in which Mary did not play a central role, by noting that it stemmed from her Orthodox childhood family. Lyyli's answer, in other words, seizes on the notion that it is natural for childhood customs to endure. The account is a good example of how the women stressed, besides the stability of Orthodox Christianity, the stability of their religion. In fact, judging from the interview material, childhood religion acted as the starting point of most of the religious lineages that they envisaged. The informants seemed to embrace the idea of a religious chain of memory primarily through concrete ties with actual people. This notion they reinforced, for instance, through emphasizing the length and stability of Orthodox "roots" within their families. Thus, they might note how their family was "fully Orthodox," how it had "lived as Orthodox for centuries," or how they had "a strong Orthodox background."

On the whole, the women regarded the religion of their grandparents as the ideal form of Orthodoxy, and considered themselves lucky for having been able to witness this way of doing religion as children. Commonly, grandparents' religion represents something into which the individual has not been fully socialized; it stands at a suitable distance from him or her to be marked as authentic and special. In their studies, both Robert Wuthnow (1999, xxxviixxxviii, 51-53) and Kaija Heikkinen (1989, 334-335, 363-364; 1984, 102-103) have also noted on the tendency of people with a lifelong religious vocation to view the religion of their grandparents' generation as unique and exemplary in its piety.

Here, I have discussed the interviewees' practice of legitimating their religious customs by placing them into a continuum of religious tradition. Although my focus has been on manners of speaking about religion, it is important to remember that one constitutive element of the lineages built by the women was their embodied history. Their bodies retained knowledge of innumerable reiterative customs and rituals that they had performed in the course of their lives. In their basic religious activities, the women often tapped into these memories, establishing lived continuums of practice. Nevertheless, chains of religious memory are often, to some extent, constructed. They are ultimately not about actual continuums but about symbolic lineages (HervieuLéger 2000, 81). The constructed nature of the continuums established by the women was revealed, for instance, in that their experience of a lineage of 
tradition was not cancelled out by breaks in its particularities. It was possible for the women to insist on a connection with childhood religion simultaneously as they recognized that, during their lifetimes, their customs had gone through significant changes.

Many religious customs that had been standard practice in the women's childhood had transformed markedly or faded away entirely in post-war Finland. These changes had also seeped into their habitus. Their bodies, in other words, also hosted knowledge of ruptures of practice. In light of all the 2oth century mutations of Orthodox culture that the interviewees had lived through, their emphasis on the stability of their religion appears to be in part a performative strategy. The description of continuums constituted a practice of speaking through which the interviewees reproduced their belief in the chain of religious memory, even in the interview situations. Moreover, it is not stretching the point to suggest that highlighting continuums was important to the women precisely because of all the changes that had gone on around them. The threat of breaks and ruptures made constant reference to the lineage all the more necessary.

According to Hervieu-Léger (2000, 75-76, 81), religion constitutes a way of believing characterized by legitimating reference to a chain of memory. In evoking the authority of this tradition, the individual expressly positions himself or herself within a community of believers. Anthropologist of religion Abby Day (2011, 48-55, 156-158, 167-169), for her part, argues that one central form of mainstream belief in the contemporary West is belief in social relationships and communities. This "belief in belonging" is performed through various kinds of acts of adherence, inclusion, and exclusion: for instance, the act of claiming a particular ethnic or religious identity. In a similar manner, constructing continuums of religious memory was a way for the women of my study to claim membership in particular communities, as well as to generate belief in them. The women's primary context of belonging was their kinship group; however, they made sure to embed this group also within wider "Orthodox" and "Karelian" communities.

\section{Living Religion, Dying Tradition?}

I met Siiri, a former librarian in her mid-seventies, at an Orthodox lay association meeting. She frequented the meetings, she explained to me, because people there sang the same songs her mother used to sing to her when she was little, and it made her "feel like home." Overall, she did not consider herself a very pious person. She did not go to church regularly; 
moreover, her domestic religious practice did not compare with that of her parents:

I feel that if we could've remained in Salmi, the whole culture would have passed on well to our generation. But, as it was, it didn't. Luckily, my elder sister and I were at an age where [later as adults] we could remember everything that they did back then. Of course, the sign of the cross was something that we were taught already when we were very small.

After she had retired, Siiri had been an active member in several Karelian associations. In one of them, she had organized a collection of proverbs and stories in the local dialect of Salmi, her Border Karelian home municipality. The collection had subsequently been archived in the Folklore Archives of the Finnish Literature Society. Nevertheless, Siiri was quite pessimistic about the future of the Karelian language in Finland. She pointed out that there were so few people still alive who had learned it as a child and could really speak it, adding: "I find it nice that the Archbishop Leo (of Karelia and all Finland) is interested in Karelian. But you can tell that he hasn't spoken it as a child. He spoke the dialect of Savonia instead, since he was born there." In the interview, Siiri also commented on the revivification project of the Karelian language currently underway in Finland, noting that, to her, the version of Karelian promoted by the Karelian Language Association sounded like a "made-up language." ${ }^{2}$ It was different from the dialect spoken in her childhood environment. "But maybe they founded the association so that the Karelian language would stay alive at least in some form," she pondered. "I can understand that."

Ethnic cultures are problematic entities. The definitions of the term "Karelian," for example, vary along historical, local, and political lines (Heikkinen 1996, 20, 30; Virtanen 1987, 185). The collective Karelian identity of Second World War evacuees took shape only in post-war Finland, in contact with non-Karelians. The gradual development of this identity is documented, for instance, in Kaija Heikkinen's work on the self-consciousness of evacuees from Salmi. In her research, Heikkinen (1996, 23-24, 28; 1989, 363-367; 1984, 84-87, 99-104)

2 The Karelian Language Association (Karjalan Kielen Seura) was founded in 1995 (Lampi 2016). A potential explanation as to why Siiri found the language promoted by the association peculiar is that the inhabitants of pre-war Salmi spoke Olonets Karelian, a dialect different from the one spoken in most parts of Border Karelia (Järvinen 2004, 26-27). 
notes that, for first-generation adult evacuees, the term "Karelian" received its meaning with respect to personally known locales such as the home village. In the minds of second-generation evacuees, it was connected to a much vaguer and more generic notion of "Karelian culture": a conglomeration of customs, artifacts, and cultural traits.

This kind of variation in ethnic consciousness is, to an extent, visible also in my material. The oldest of the women often spoke of Karelia on the basis of their own childhood experiences. On occasion, these informants also commented on the ethnic labels given to elements of their pre-war surroundings, stating, for instance, that Karelian roast (karjalanpaisti) or Karelian pasties (karjalanpiirakat) actually had an altogether different name in their childhood. The youngest interviewees, for their part, were more prone to basing their accounts on generalizing discourses. Nevertheless, irrespective of age the women spoke of "Karelian" practices also when referring to religious, and specifically Orthodox, customs. In their understanding, Karelian culture and Orthodoxy were intertwined, even though they were aware that not all of prewar Finnish Karelia was Orthodox in its religious affiliation.

The women's reactions to contemporary discussions concerning Karelian culture are evident, for instance, in how they employed the term "tradition" in connection with their religious practice. In the interviews, I asked the women a few questions built around the term. The dictionary definition of "tradition" (perinne) is inherited custom, practice, or knowledge (Grönfors 2006, 472). In their answers, the interviewees usually brought up an additional connotation: past custom that is no longer part of mainstream culture. All in all, they did not use the word very often. Moreover, they used it particularly infrequently when describing their religious practices. It was rare for them to label as traditions those religious customs that they actively observed, even though they were keen to emphasize the continuums established through these customs. The women, in other words, tended to distinguish traditions from continuums of religious practice.

Whereas most of the women spoke of traditions, if at all, as concrete customs, some of them made spontaneous use of the term as referring to an abstract body of knowledge. To speak of tradition in this sense, particularly when it is a tradition in which one participates, requires a certain amount of critical distance (see also Heikkinen 1984, 102; Riesebrodt 2010, 16). Consider, for example, Auli's statement: "You can look at tradition from different angles: poetic tradition, costume tradition, culinary tradition, religious tradition, everything. I like to combine these together. They make a person a totality, all this tradition." Auli was one of the youngest of my interviewees; her approach 
differs greatly from the intuitive distance-taking from "tradition" exhibited by the older women.

As regards the continuum of cultural customs, the informants conveyed a strict ideal according to which customs survive only through active practice. They have to be observed in everyday life to stay alive. Furthermore, what this implies is that to be able to keep customs alive, the individual has had to be acclimated into using them, preferably within the childhood family. In the women's opinion, socialization into a culture was thus ultimately the only successful way of transferring it on. This notion is evident, for instance, in Siiri's above laments on how evacuation from Karelia hindered the passing on of Karelian culture, religion, and language.

Now, in their accounts, the interviewees usually connected the term "tradition" with customs that were no longer kept alive in this way. Hence, they did not often speak of Orthodox practices as traditions. When they did use the term, they referred to childhood religious customs that had later waned away. Furthermore, the women also spontaneously defined certain religious practices as "Karelian." Commonly, these were also practices that did not feature in mainstream Finnish Orthodox culture any longer. In the women's parlance, overall, the term "tradition" was most often linked to religious practices also described as "Karelian."

The women were quite unanimous in that Karelian culture will go through major changes after those who have personally experienced pre-war Karelia have passed away. It "fades away," "transforms," "ends," "is buried along with us," "becomes Finlandized," "becomes confused," or "merges" with the dominant culture were some of the expressions they used. The Orthodox Easter practice of symbolically birching (virpoa) family members, relatives, and livestock on Palm Sunday provided one negative example of the mutation of Karelian customs in post-war Finland. ${ }^{3}$ In most parts of the country, this practice has merged with the western Finnish custom that involves children dressing up as Easter witches (trullit) on Great Saturday, and the women did not think well of the resulting hybrid. Siiri, for example, mentioned: "I'm so sad that birching has lost, has changed entirely. It has blended into this Ostrobothnian tradition. For I remember how we [as children] started off early in the morning, and ran in the snow [to bless our aunt next door]."

3 Birching involves waving a decorated willow branch that has been blessed at church in front of a person whilst reciting a short rhyme. Afterwards, the willow branch is given to the person in question in exchange for a payment in the form of a treat or money (Korjonen-Kuusipuro and Niinisalo 2005, 53-55; Sarmela 2009, 268-269). 
Moreover, one cause of sorrow that the women brought up was the diminishing role of Karelianness in the Orthodox Church. The interviewees recounted how Orthodox lay association meetings used to be gatherings where participants spoke Karelian, remembered Karelian customs, and sang Karelian songs. Nowadays, this emphasis on Karelia had, to some extent, faded away. The women could also note how, in the past, the majority of priests were Karelian evacuees, while today many of them had no connection with Karelia. All in all, the community included an increasing number of people in whose minds Orthodoxy was not linked with Karelia. In consequence, the Finnish Orthodox Church seemed no longer to represent quite the same lineage of religious memory with which the interviewees identified. It had too little to do with Karelia.

Starting from the 196o's, some elements of Karelian folk religion have become the target of rekindled popular interest. Karelian associations, cultural heritage foundations, and the tourism industry have organized projects of revivification of various Karelian traditions (Petrisalo 2001, 64-106; Raivo 1996, 205-238). In the process, they have given rise to folklorized practices to represent "exotic" and "authentic" Karelian culture. At some point in their lives, most of my interviewees had also participated in the activities of some Karelian association or other. Nevertheless, at least some of the recent revivification efforts appeared "artificial" and "forced" to them.

The practice of ritual lamenting (äänellä itkentä) is one Orthodox Karelian tradition that has gone through a kind of revival in present-day Finland. ${ }^{4}$ When asked to give their opinion on this development, most of the women noted that they accepted the active resuscitation of customs, if the custom in question had completely died out. However, they often also noted that the result was something quite different from the original practice. The lamenters of the past, after all, learned the skill through growing up within a culture of lamentsinging, not through express study. Furthermore, some of the interviewees even expressed the opinion that the custom should rather be allowed to vanish than transform into something that was not true to the spirit of the original.

4 In pre-modern Karelia, lament-singing was women's tradition. Lamenting was part of rites of passage; in addition, women sang laments about their personal sorrows (Keinänen 2014, 25-30; Nenola 2002; Utriainen 1998a). In inter-World War Border Karelia, the practice of lamenting was already waning, and in post-war Finland it all but died down (Tenhunen 2006, 181-184). In the 1960s, however, lament-singing started to attract attention as part of a newfound interest in folk music, folk traditions, and Karelian culture. Courses of lamentsinging have been organized since 1998, and Äänellä Itkijät, the association of lamenters, was founded in 2001 (Tenhunen 2006, 188-196, 293-310). 
Above, I have traced descriptions concerning ruptured continuums of practice from the displaced Karelian Orthodox women's accounts regarding the present and future of Karelian culture in Finland. All in all, the interviewees' descriptions showed a discrepancy between how customs ideally stay alive, and how Karelian culture was currently being sustained in Finland. Their reactions concerning the mutation of individual practices, moreover, seemed to reflect their embodied history with respect to these practices. If the women had past experiences of a particular practice as part of the overall way of life, they often held reservations regarding later changes. Lacking such personal experiences, they were commonly more ready to accept the evolution of the practice. This explains why the younger informants were generally more open to projects of active revivification than the older ones. Ultimately, then, the crux of the matter was not the mutation of practices as such. It was their changing in ways that, in the embodied experience of the women, broke the continuum with the earlier form. In the informants' understanding, ruptures in the lineage made "traditions" out of religious practices. Hence, their stress on the continuums inherent in their religious customs: continuums testified to their religion remaining alive.

\section{Religion versus the Secular World}

A defining feature of what can be understood as the late-modern condition is that there is no longer a single truth or way of life to follow. Present-day Western societies are characterized by an unprecedented proliferation of morals, religiosities, and lifestyles. This backdrop of pluralism, moreover, affects every individual, even those who remain drawn to more traditional understandings of, for instance, religion and gender (Beck and Beck-Gernsheim 2002, 1-8; Vincett, Sharma, and Aune 2008, 8). According to the interviewees, the overall status of religion in Finland had deteriorated during their lifetimes. This they saw as a clearly negative, even alarming, development. Often, the women stated that people seemed to need religion less than they had during the Second World War and in the post-war period. Furthermore, what diverted their attention away from the church was secular pastimes and material pursuits. Thus, Rauha, for example, stated: "People are in an awful hurry, that's what does it. They cannot quiet down. Is it a lust for money or what? Everything has to be perfect in their lives, perfect. People should be content; we have a really good life."

In connection with the diminished role of religion in today's Finland, the women took up the theme of changing morals. They could state, in worried tones, that human life was no longer respected in the same way as before: 
suicides, domestic violence, bad manners, and abandoned children and old people were all proof of this. Moreover, the informants also reflected that people today "live only for themselves" and do not care enough about others, a development directly commensurate with marriages having become much weaker and divorces more common than before. In addition, they might imply that the pursuit of gender equality had gone too far, and was corrupting the morals of young women, in particular. All of these things, the women conveyed, were ultimately connected to people turning away from religion.

These opinions parallel the results of previous studies on the values of Finns of the same generation (Kääriäinen, Niemelä, and Ketola 2005, 153-163; Ketola, Kääriäinen, and Niemelä 2007, 61-62, 67-69). To an extent, the interviewees' accounts also replicate Abby Day's (2011, 144-150, 198-201) observation that many Westerners connect moral decline with the changing status of women. In this vein, the informants seemed, on some level, to put a lot of the blame for the corrosion of values on women. At least, many of their examples concerning the morals of the "olden days" involved women complying with their traditional roles as self-sacrificing caretakers of their loved ones.

On a contrary note, when speaking of contemporary religiosity, the interviewees could also note that, at present, many people were actively searching for a spiritual alternative fit for them. If they found one, they made a conscious decision to have religion as part of their lives. Elsa, for instance, observed: "I have this feeling that today people seek a lot, at least in Finland. It's clearly visible." And Kirsti contemplated: "To the people of the war-time, religion was self-evident. They had been on the front, they had gone through evacuations, all that. But for the people of today it's a conscious choice. Either you need the Church and God, and you pray, [or not]. It's a whole different mentality compared to when everyone believed." These kinds of reflections reveal the women's awareness of the contemporary notion of religion as an individual choice reflecting one's authentic self (see e.g., Beckford 2003, 209-213).

In a previous chapter, I discussed the informants' capacity to reflect on the differences between their religion and the religion of Lutherans and converts to Orthodoxy. The accounts discussed above also show the women comparing their religion to that of others. In Elsa and Kirsti's case, for example, the other in question was a style of doing religion that placed less importance on family tradition than on finding a lifestyle that spoke of one's individuality. However, the primary other in contemporary Finland against which the women positioned themselves was not, in the last instance, any religious way of life. It was secular society.

Perhaps as a reaction to being interviewed by a member of the academic community, some of the informants spontaneously rose to defend their beliefs 
and practices against hypothetical secular opposition. They voiced different skeptical arguments concerning religion, such as the point that religious assertions cannot be scientifically proven, and the notion of religion as the opium of the masses. Elsa, for example, pondered: "Sometimes people say that belief and God are crutches for the weak. Well, what if this is true? What does it matter? It's a good thing, right? Although, when it's said by a person who doesn't believe in God, the whole statement receives a completely different meaning." In taking up these kinds of arguments, the women recognized the existence of secular and anti-religious worldviews, positioning themselves in relation to them.

When speaking of the religion of Lutherans and converts to Orthodoxy, the women often appeared convinced of the validity of their own position with respect to the alternatives under consideration. In comparisons between religious and secular discourses, they did not sound so confident. On the contrary, they seemed to acknowledge the dominant status of scientific arguments and the weakness of their own stance with respect to these discourses. In this vein, Elsa reflects that the interpretation given to the notion of God as a crutch depends on the person's belief in God. What she alludes to is that, ultimately, her own position comes down to belief. The act of placing one's trust in God strikes those who do not believe, but look for scientific verification, as completely irrational.

Overall, in their reflections concerning contemporary Finnish society, the Orthodox women commonly distanced themselves from the present, siding rather with the past. Nevertheless, the accounts also reveal the influence of contemporary currents of discourse on their views on religion - even if they did not advocate these discourses themselves. That Elsa, for instance, would spontaneously launch into the kind of rumination quoted above is a reflection of her being affected by secular ways of thinking, discourses that bring into question the soundness of her belief in God. Furthermore, when describing modern lifestyles, the women sometimes admitted that the changes they spoke of affected them as well, to some extent. They could note, for example, that their lives had gotten somewhat hectic too: they were spending too much time on various secular pastimes. In addition, they also pointed out changes for the better, such as increased equality and tolerance. Through such comments, the women conveyed that they did not downright reject the contemporary way of life. They were both outsiders and insiders to it.

Auli: I've tried those more secular ones (lifestyles) too, at some point. But I never succeeded in them that well; this (Orthodoxy) has suited me better. If I've started thinking that 'I have the right' and that 'I can do that as well', I've become miserable. (...) Nowadays a woman is considered 
old-fashioned if she doesn't follow all these things. You should be somehow different, but it doesn't work out for everyone. For me, it didn't bring that; I always had to get back in line.

The above account is a beautiful illustration of the complex relations that the interviewees could harbor with particular discourses topical in present-day Finland. Auli makes insightful observations concerning what is expected of women in today's society, acknowledging her shortcomings with respect to the norm. Nevertheless, she also notes how, to her, a more traditional gender role has simply felt the right way to be. Auli's account, in a sense, reflects the layered constitution of her gendered habitus. It shows how she had been affected by contemporary standards (she was aware of them, and had even tried to adopt them), but also reveals the impact of her embodied history. Ultimately, Auli felt most comfortable in acknowledging the pull of the native layer of her habitus, the dispositions set deepest within her.

In the above excerpt, Auli explains how experimenting with individualistic lifestyles made her "miserable." However, in the course of their religious lives the women had also made individualistic choices, even though they did not advertise them as such. One such choice was their standing by their religious heritages even when marrying Lutheran men and becoming mothers of Lutheran children. In the women's parlance, this course of action was founded on their strong bond with the Orthodox religion. It was impossible for them to give up something that was "in their genes." From the perspective of the adult family, however, this can be seen to constitute an individualistic decision. Even though resigning one's childhood religion was not uncommon among members of the Orthodox Church during the first post-war decades, the interviewees had not done so. In contrast to those who had converted, and to those who had adopted secular lifestyles, they had made a conscious choice to remain Orthodox.

\section{On the Religion of Children and Grandchildren}

The women's interview accounts concerning the baptism of their children into the Lutheran faith mirrored the post-war mentality of keeping a low profile about one's Orthodox affiliation. They usually commented on the issue by stating how it was the "custom of those days" or the "letter of the law." These expressions treat the baptism of children into the father's faith as standard policy that was not challenged by any parties involved. Some interviewees, moreover, implied that Lutheranism had appeared the superior alternative because 
of the low status of Orthodox Christianity during the first post-war decades. Martta, for instance, stated, of her children: "They're Lutheran. At that time you weren't. At that time, you had to be careful, or were careful not to tell others of your Orthodoxy."

Regretting the religious affiliation of their Lutheran children was something that most of the informants did not admit to. When asked about it outright, they instantly denied such feelings. According to the women, the Lutheranism of their children was "natural"; after all, "we all believe in the same God." Moreover, it reflected the "spirit of the time." Elsewhere in the interviews, some of them implied that the issue had not actually been quite that simple, mentioning, for instance, that it would have been nice to socialize the children into the religion they themselves practiced. Nevertheless, the only woman who expressed open regret was Maija-Liisa whose children had been born after the reform in the law concerning baptism. She was deeply sorry that she had "let" her children become Lutherans, thus "severing the Orthodox roots" of her family.

The women's descriptions of the religious socialization of their Lutheran grandchildren exhibited a similar logic to their accounts of the religious upbringing of their children. The interviewees seemed to think that it was acceptable to explain Orthodox practices to Lutheran descendants, but inappropriate to actively lead them towards an Orthodox lifestyle. However, since the women did not consider themselves primarily responsible for the religious education of their grandchildren, they were, in some sense, more free to introduce them to the Orthodox heritage of the family. Over the decades, the general attitude towards Orthodoxy had also become more approving, which may have encouraged them in this task.

Compared to the women with Lutheran children, those with all-Orthodox adult families depicted the religious socialization of their offspring as a less problematic affair. As to the transfer of Karelian customs, however, all of the interviewees were more or less facing the same situation. In the interviews, they spoke about remembering the Karelian way of life for the benefit of their children and grandchildren, and about teaching their children and grandchildren individual customs: the baking of Karelian pasties, words or nursery rhymes in the Karelian language, and so on. These measures, however, were in obvious contrast with their own experiences of being socialized into Orthodox and Karelian culture.

Helena: How do you see your role, if you think of a lineage of generations, for instance, from you grandparents to your grandchildren? What's your place there? 
Sinikka: Well it has surely changed from the time of my grandparents and parents. In any case, I try to tell these little ones of my life and my traditions, what they did in Karelia and ... But I don't know whether they'll be interested in these things later.

When evaluating their own contribution to the passing on of Orthodox and Karelian customs within their adult families, the tone of the women varied. Whereas some lamented on not having taught their children enough, others, similar to Sinikka, implied that they had done what they could under the circumstances. These reflections show the women judging their activities based on contemporary criteria, knowledgeable of the changing possibilities for passing on religious and ethnic customs compared to earlier times.

An important characteristic of the interviewees' descriptions was an emphasis on not forcing their ways on their descendants. Martta, for example, noted: "I've told [of Orthodox and Karelian practices] in passing. But I've never imposed them on the grandchildren in any way." And Anna stressed: "I've not pressed anything on them (the grandchildren). I've only told of how much they (Orthodox customs) mean to me." These kinds of remarks reflect the women's adaptation to the individualistic ethos of the surrounding society. Moreover, they also allude to a crucial change in conditions of religious and ethnic socialization compared to the women's childhood. As children, the interviewees learned the lifestyle of their parents more or less automatically. In contrast, their own work on this front was more of a conscious effort. Due to their minority status and overall social changes, the women's lifestyle differed, in some important ways, from that of their spouses and the surrounding society. Hence, they were not able to present it to their descendants as doxa, but only as one possibility among others.

Overall, the women spoke of the religion of their children and grandchildren with reflective tones. They pondered on the effects of home upbringing, schooling, the church, the surrounding society, and specific life events on their descendants' religiosity. It was common for the women with Orthodox children to produce more straightforward judgments, either positive or negative. Thus, while some of these women spoke of their children as "conscious" or "true" Orthodox, others lamented that their children were not sufficiently interested in religion. The interviewees with Lutheran children, for their part, used a milder, cautiously positive tone. They rarely offered general evaluations, but approached the topic through mentioning particular religious customs that some of their descendants had adopted. It is possible that these women knew, on average, less about their children's religious activity than the women 
with Orthodox children. Alternatively, they may also have been less comfortable with discussing the topic in the interviews.

Generally speaking, the women with Lutheran children and grandchildren spoke more of their offspring's interest in Orthodox and Karelian culture than of their religiosity. These descriptions, moreover, varied a great deal between informants. Some of the women proudly explained, for example, how their children and grandchildren "knew everything" about their background, or how they were "extremely interested" in Orthodox and Karelian customs. At the same time, others were less optimistic in their statements, noting, for instance, how their descendants had a "positive attitude towards traditions but didn't continue them," how they "didn't know enough" about their roots, or how they "didn't want to talk about the past at all." In all likelihood, the range of these comments corresponds with actual differences in the religiosity and ethnic consciousness of the informants' children and grandchildren. However, the variation also reflects their chosen perspectives. When the women compared their offspring's activities with their own practices, their judgments were often negative in tone. Whereas, if they evaluated their descendants against the background set by present-day society, their estimates were characterized by a more positive outlook.

On the whole, the women acknowledged that their descendants' religion was of a different order compared to their own. This shows, for example, in their remarks treating the religion of their children and grandchildren as a personal choice. In this vein, Soja stated: "I taught my children all the prayers. Even to these bunukat (grandchildren) I taught mealtime prayers and bedtime prayers, among other things. But it's their own business, whether they remember them or not." Such interpretations differ greatly from how the women talked about their religiosity. This capacity to fluently switch to an individualistic discourse when speaking of children and grandchildren shows the interviewees' awareness of how religiosity is commonly thought about today. It is an expression of the multi-layered constitution of their habitus: of the influence of today's pluralistic and individualistic social climate on their embodied knowledge concerning religion.

I end this section on a personal note. As has been extensively discussed in the course of the book, a central anchor of the interviewees' religiosity was their family heritage. Alas, the majority of them had not been able to pass this heritage on as an active lifestyle to younger generations. During the research process, I often found myself moved by this, in my opinion, tragic state of affairs. In part, this emotional reaction resulted from my earlier experiences. In the early stages of the research, my idea had been to gather information from women of different ages. In this scenario, the research would have 
discussed variations in Orthodox religiosity and Karelian identity between generations. However, I soon abandoned this plan due to the lack of interest from the part of younger women towards my project. I was simply not able to attract the attention of people younger than, say, 60 with my presentations or letters. Later, I realized that my failure was symptomatic of a more general development, one that the interviewees experienced also within their families.

According to Robert Orsi $(2005,77)$, children "signal the vulnerability and contingency of a particular religious world," which is why "discussions of children's religious lives are fraught with such great fear, sometimes sorrow, and sometimes ferocity, (...) especially in times of social change or dislocation." Orsi is obviously right in emphasizing the crucial value of children to the future of most religions. The Orthodox women, however, commonly spoke of their children's and grandchildren's religion calmly and laconically. Early on in the analysis, I found their accounts baffling. Why did they not express more regret, sadness, or anger over not having been able to secure the continuum of their practices across generations? After some consideration, I came up with several potential explanations to their remarks.

First of all, the descendants' religion was one of those themes that clearly suffered from my decision to interview each informant only once. Several women were hesitant to dwell on the topic so as not to violate their children's privacy. Secondly, the women may also have found it difficult to integrate the issue to the autobiographical narratives they were producing. On some level, after all, it challenged their overall emphasis on lineages of religious practice. In light of this, it is possible that the interviewees hid at least some of their disappointment regarding the religion of their children and grandchildren from me. Finally, it is also important to remember that the key event for the intergenerational continuance of most women's religious heritage, the baptism of their first child, had taken place several decades, even over half a century, ago. The informants had had ample time to process the consequences of this event, and subsume them into their life stories. As for my emotional reaction to their narratives, it was immediate and spontaneous.

\section{A Grass-roots View on the Religious Field}

Practices are generated in the encounter of habitus and field, of history incorporated in bodies and history objectified in social structures (Bourdieu 2000, 150-151). My inquiry into the religious practice and habitus of the evacuee Karelian Orthodox women in the course of this and the previous chapters has therefore also opened up a view into the Finnish religious field. In this 
concluding section of the analysis, I discuss the interviewees' perceptions of contemporary religion as self-positionings within the religious field. That is to say, I treat these reflections as a grass-roots account of the religious field, mirroring the field's network of positions as it appears from the place occupied by the women.

In the interviews, I did not ask the women specifically about Orthodox priests or the hierarchy of the Church. Their spontaneous mentions of priests were mostly positive in tone. The informants could, for instance, speak of a certain priest when describing rituals that he had conducted. Moreover, they sometimes also sought to legitimize their claims by noting how a particular priest had originated or sanctioned them. Some interviewees produced critical remarks concerning, for example, priests' negative attitudes towards female priesthood, their convert backgrounds or bad parish management. These comments were made in a veiled form, or only after I had turned off the recorder, which suggests that, in all likelihood, the women refrained altogether from expressing some of their negative opinions to me. Nevertheless, the majority of their accounts signaled their recognition of the power of Orthodox religious specialists, and their partial misrecognition of the arbitrariness of this power (see Bourdieu 1971a, 304-305; Bourdieu 1991a, 9).

In their accounts, on the whole, the interviewees constructed relations primarily between different religious groups and classes of religious practitioners, while observations on the relationship between laymen and religious specialists were less common. This, I suggest, reflects their perspective on the configurations of the religious field. From where the women stood, the most important demarcation lines stretched, indeed, between various types of lay practitioners, and not between laymen and priests.

From the interviewees' point of view, Lutherans occupied a central rival position within the religious field. Even though increasing immigration and religious pluralization were topical questions in Finland already in 2007 and 2008 , only a minority of the women spoke to me of any other Churches or religions. Tarja's account, below, provides a global perspective on the religious field, rare in the material as a whole. In fact, many of the interviewees seemed to still feel, of the Lutheran Church, somewhat like Tarja had when she was young: "When you think of how many Muslims and others there are in the world, you come to realize the size of the Lutheran community. (...) Of course, they're the mainstream here. It (the Lutheran Church) felt so big when I was little, and then it just got smaller and smaller in my eyes. It came to feel like a needle in a haystack when compared to all these other religions." Furthermore, within the Orthodox subfield of the Finnish religious field, the women outlined positions for Karelians, non-Karelians, converts, and non-converts. They could also 
mention the growing number of Russian immigrants in the Church. Often, however, they had had little actual contact with these congregants.

The women's perceptions of all these groups paralleled the groups' relative status with respect to each other. The changing power dynamics within the religious field were visible, for instance, in the interviewees' expressions of superiority with respect to Lutherans, and in their somewhat defensive remarks concerning various factions gaining ground within the Orthodox community. Thus, the women's comparisons between their religion and that of others actually revealed their investment in struggles of the religious field. For example, in emphasizing the continuums of memory sustained in their religious practice, they made use of the symbolic resources of the Orthodox Church to promote a particular definition of proper Orthodoxy. In so doing, they also strived to augment their status within the field.

The individual's habitus does not automatically stay attuned to a particular field. Due to the evolution of either habitus or field, the two may fall out of pace with each other (Bourdieu and Wacquant 1992, 130-131; Bourdieu 2000, 160-162). The women's interview accounts suggest that this is what had happened to them: their habitus lagged behind some of the recent evolutions of the Finnish religious field and its Orthodox subfield. Concerning the prominent role of converts in today's Orthodox community, Rauha, for example, stated: "There are a lot of [converts here]; even our priest is a convert. But, I don't know. I've begun to think that I believe in the old ways. There's so much that's new; I don't believe in all of it. Like these converts ordering us around at church, to do this and that. It hurts me so." Rauha's talk of belief is symptomatic in that mismatch between habitus and field is prone to undermine practical belief in the field in question, at least on some level.

Overall, the interviewees' balancing acts between the past and the present constituted efforts to secure for oneself a comfortable enough position in the contemporary religious field, considering the massive changes that the field had undergone. For instance, the instinctive aversion that the women harbored towards the term "tradition" in connection with their religious practice can be seen to reflect their deep awareness of the changes that had taken place in standard everyday Orthodoxy during their lifetimes. The women no longer represented mainstream Finnish Orthodoxy. In some ways, their religion had more in common with the past than with the present of Finnish Orthodox Christianity. By emphasizing the difference between their religion and tradition, the interviewees reacted against the threat of being relegated squarely to the past, amidst other relics of "Karelian Orthodox tradition." They fought for the enduring relevance of their type of religion within the Orthodox field (see also Bourdieu 2000, 212-213). 
The disparity between the informants' habitus and the contemporary religious field was also evident in their interpretations of religious capital. The individual's religious capital is closely tied to his or her dispositions, competences, and knowledge concerning matters of religion (Verter 2003, 162). In other words, it is a product of his or her religious trajectory, like habitus. At any given moment of time, dominant conceptualizations of religious capital reflect the state of the religious field (Bourdieu 1971a, 318-319: Bourdieu 1991a, 22). They are influenced by the power relations between different actors inhabiting the field, the articulated distinctions between their habitus, and the supply and demand of religious resources.

The women appreciated such forms of piety as continuing family religious traditions, staying true to one's childhood religion, the "living" of religion, and the "remembering" of God. For them, the religion of their grandparents' generation commonly represented the ideal form of lay Orthodox practice. In a sense, the women described their understanding of religious capital and of meritorious religious behavior precisely through describing the religiosity of their grandparents. Nevertheless, they were also aware that this understanding of religious capital was not universally shared within the Finnish religious field. In the course of their lives, the dominant currencies within the field had changed. The doxic religiosity valued by the women had been contested, and in many cases overcome, by styles of spirituality that did not emphasize the importance of following the ways of one's ancestors. The interviewees' embodied knowledge concerning these changing values within the field was evident, for example, in their comments concerning the religion of their children and grandchildren.

Helena: Well, how do you see your position within, if one thinks of, like, a chain of traditions? Your father was the one primarily teaching you these things...

Ilmi: Of course, it isn't like it was [before]. It'd be nice to pass on these traditions to the grandchildren. But they all live so far away. It's, in practice, impossible.

Helena: Have all your grandchildren been baptized into Lutheranism?

Ilmi: Yes, they are all Lutherans.

Helena: Well, does it bother you that they are Lutherans? Or, does it matter what Church they belong to? 
Ilmi: Regrets don't, they don't accomplish anything. You have to act on the basis of what you're given. Empty fantasies get you nowhere.

The above excerpt demonstrates the laconic tone often adopted by the women when speaking about their offspring's religion. Ilmi does not seize on my invitations to mourn for the discontinuation of her Orthodox heritage in the younger generations; instead, she stresses her powerlessness in the matter. According to Ilmi, she had not been able to participate much in the religious and ethnic socialization of her grandchildren due to practical reasons. Behind such practicalities, however, often lie values. Today, the passing on of cultural knowledge and skills from grandparents to grandchildren is a less appreciated mode of socialization than it was at the time of the women's childhood. The capital value, in Bourdieuan terms, of such inherited knowledge has decreased (see also Calhoun 1993, 79-80). Moreover, that Ilmi did not possess the authority to (or did not want to) press for the baptism of her children into the Orthodox faith can also be regarded as a question of capital. At the time of the children's birth, an Orthodox affiliation and an Orthodox habitus did not translate into positive resources within the religious field.

Ilmi's account, all in all, echoes her embodied knowledge of her limited leverage as to the religion of her children and grandchildren. She seems to have contented herself with the idea that the matter had not been within her sphere of influence to begin with. The same resigned attitude is discernible also from the accounts of many other women. Nevertheless, Ilmi's rather dismissive talk of "empty fantasies" also speaks of disappointment. In an ideal world, things would have been different.

Ultimately, the interviewees' accounts concerning both contemporary religion and the religion of their offspring convey positional suffering. According to Bourdieu (1999a, 4), this type of suffering can be caused by low status within a field, outdated habitus, or lack of capital. Positional suffering does not necessarily involve material destitution; it is about marginalization with respect to the game played in a particular field. From accounts such as Ilmi's, one can trace the women's experiences of displacement within the Finnish religious field. They illustrate what it means to be in possession of an Orthodox habitus in a Lutheran world, and the habitus of a "religious dweller" in a world increasingly dominated by "religious seekers" (see Wuthnow 1998, 3-11). 